\title{
Effect of transient receptor potential vanilloid 4 activation on the delayed rectifier potassium current in the hippocampal pyramidal neurons and Kv subunit expression in the hippocampi of mice
}

Li Zhou

Nanjing Medical University

Weixing Xu

Nanjing Medical University

Dong An

Nanjing Medical University

Chen Men

Nanjing Medical University

Yingchun Li

Nanjing Medical University

Yimei Du

Huazhong University of Science and Technology

Lei Chen ( $\nabla$ chenl@njmu.edu.cn )

Nanjing Medical University https://orcid.org/0000-0002-7382-8306

\section{Research}

Keywords: calcium/calmodulin-dependent kinase II, hippocampus, Kv subunit expression, pilocarpineinduced status epilepticus, transient receptor potential vanilloid 4, voltage-gated potassium channel

Posted Date: April 29th, 2020

DOl: https://doi.org/10.21203/rs.3.rs-24895/v1

License: (c) (1) This work is licensed under a Creative Commons Attribution 4.0 International License. Read Full License 


\section{Abstract}

Activation of transient receptor potential vanilloid 4 (TRPV4) can increase hippocampal neuronal excitability. Recent studies have reported that TRPV4 may be involved in the pathogenesis of epilepsy. Voltage-gated potassium channels (VGPCs) play an important role in regulating neuronal excitability and abnormal VGPCs expression or function is related to epilepsy. Activation of TRPV4 can modulate ion channels, but whether activation of it could modulate VGPCs in hippocampal neurons remains unknown. Here we examined the effect of TRPV4 activation on the delayed rectifier potassium current $\left(I_{K}\right)$ in the hippocampal pyramidal neurons and on the Kv subunits expression. We also explored the role of TRPV4 in changes in $\mathrm{Kv}$ subunits expression in mice following pilocarpine-induced status epilepticus (PISE). Application of TRPV4 agonists, GSK1016790A and 5,6-EET, markedly reduced $I_{\mathrm{K}}$ in the hippocampal pyramidal neurons, shifted the voltage-dependent inactivation curve to the hyperpolarization direction, and had no effect on the voltage-dependent activation curve. GSK1016790A- and 5,6-EET-induced inhibition of $l_{K}$ was blocked by TRPV4 specific antagonists, HC-067047 and RN1734. GSK1016790Ainduced inhibition of $I_{K}$ was markedly attenuated by calcium/calmodulin-dependent kinase II (CaMKII) antagonist, but was not affected by protein kinase $\mathrm{C}$ or protein kinase $\mathrm{A}$ antagonists. Application of GSK1016790A for up to $1 \mathrm{~h}$ did not change the hippocampal protein levels of Kv1.1, Kv1.2, or Kv2.1. Intracerebroventricular injection of GSK1016790A for $3 \mathrm{~d}$ reduced the hippocampal protein levels of Kv1.2 and Kv2.1, leaving that of Kv1.1 unchanged. Kv1.2 and Kv2.1 protein levels were reduced markedly in hippocampi on day 3 post PISE, which was significantly reversed by HC-067047. We conclude that activation of TRPV4 inhibits $I_{\mathrm{K}}$ in the hippocampal pyramidal neurons, possibly by activating CaMKII. Persistent activation of TRPV4 decreased Kv1.2 and Kv2.1 expression, which may be associated with the decrease in Kv1.2 and Kv2.1 expression following PISE.

\section{Introduction}

Voltage-gated potassium channels (VGPCs) play an important role in regulating neuronal excitability [1]. Activation of VGPCs mediates outward potassium current, which is responsible for membrane repolarization, and thus controls the duration, shape, and firing frequency of action potentials (APs) [1]. In the hippocampal neurons, voltage-gated potassium current mainly consists of two components, delayed rectifier $\left(I_{K}\right)$ and fast transient potassium $\left(I_{A}\right)$ currents, which can be separated by their biophysical and pharmacologic properties [2]. $I_{\mathrm{K}}$ keeps single AP short and permits the high-frequency trains of APs firing, and $I_{A}$ helps a cell fire at low frequency and promotes the broadening of APs during repetitive activity [1, 2]. VGPCs are encoded by 40 different genes and categorized into 12 subfamilies (Kv1-Kv12). Kv1.1, $\mathrm{K}_{\mathrm{V}} 1.2$ and $\mathrm{Kv} 2.1$ are the main $I_{\mathrm{K}}$ subunits in the hippocampus $[3,4,5]$. Changes in VGPC expression or function result in abnormal neuronal excitability and are related to nervous system diseases [6].

Transient receptor potential vanilloid 4 (TRPV4) is a member of the vanilloid transient receptor potential channel family and is permeable to calcium $\left(\mathrm{Ca}^{2+}\right)$ [7]. Activation of TRPV4 can increase hippocampal neuronal excitability through $\mathrm{Ca}^{2+}$ influx mediated by the receptor per se or by modulating the ion 
channels or excitatory/inhibitory neurotransmitter systems $[8,9,10,11,12]$. Activation of TRPV4 modulates VGPCs in the trigeminal ganglion neurons and calcium-activated potassium current in the endothelium and smooth muscle cells $[13,14,15]$, but whether activation of TRPV4 could modulate $I_{K}$ in hippocampal neurons remains unknown.

Epilepsy is a common neurological disorder characterized by recurrent spontaneous seizures because of hyperexcitability and hypersynchrony of the brain neurons [16]. The mechanisms underlying epileptic seizures are complex and still ambiguous, but evidence suggests that channelopathies can cause epilepsy $[17,18]$. Considering that VGPCs play critical roles in modulating neuronal excitability, abnormal VGPCs expression or function has been reported to be related to epileptic phenotypes. For example, deletions or mutations in genes encoding Kv1.1 subunit result in spontaneous seizures similar to those observed in the case of temporal lobe epilepsy (TLE) [19]. Kv1.2 was significantly downregulated in autosomal dominant lateral temporal epilepsy [20]. In recent studies, the involvement of TRPV4 in the pathogenesis of epilepsy has been reported [21, 22]. TRPV4 expression was found to be increased by pilocarpine-induced status epilepticus (PISE) [21]. Blockage of TRPV4 could inhibit hyperthermia-induced seizures in the larval zebrafish forebrain [23]. Application of TRPV4 antagonists markedly attenuated the neuronal death after the induction of status epilepticus [22]. These results indicate an involvement of TRPV4 in the pathogenesis of epilepsy.

The effects of TRPV4 activation on $l_{K}$ and the expression of $I_{K}$ subunits in the hippocampus may provide more evidence for the mechanisms underlying TRPV4-induced modulation of hippocampal neuronal excitability. Whether TRPV4 is involved in the changes in $I_{K}$ subunits post status epilepticus may help to understand the mechanisms underlying TRPV4-involved in the pathological process of epilepsy. However, none of the studies have evaluated these so far. Therefore, in this study, we aimed to examine the effect of TRPV4 activation on $I_{K}$ in the hippocampal pyramidal neurons and the expression of Kv subunits in the hippocampus, and then explored the association between TRPV4 and changes in Kv subunits in PISE mice.

\section{Methods}

\section{Experimental animals}

ICR Mice (Oriental Bio Service Inc., Nanjing, China) were used in this study. All mice were housed in the Animal Core Facility of Nanjing Medical University under a 12:12 h light/dark cycle at a temperature of $23 \pm 2{ }^{\circ} \mathrm{C}$ and humidity of $55 \pm 5 \%$; free access to food and water was provided. This study was conducted in accordance with the Guidelines for Laboratory Animal Research set by Nanjing Medical University. All the animal experiments were carried out in accordance with the National Institute of Health Guide for the Care and Use of Laboratory Animals (NIH Publications No. 80 - 23) revised in 1996 and approved by the Ethics Committee of Nanjing Medical University (No. IACUC-1811044). All efforts were made to minimize animal suffering and to reduce the number of animals used. 


\section{Slice Preparation}

The mice (10-15 days old) were decapitated after they were anesthetized with diethyl ether, and subsequently, the brains were rapidly excised. Coronal brain slices ( $400 \mu \mathrm{m}$-thick) were cut using a vibrating microtome (Microslicer DTK 1500, Dousaka EM Co., Kyoto, Japan) in ice-cold artificial cerebrospinal fluid (ACSF), as reported previously. The ACSF, which was composed of (in mM) $125 \mathrm{NaCl}$, $2.5 \mathrm{KCl}, 1 \mathrm{CaCl}_{2}, 1 \mathrm{MgCl}_{2}, 26 \mathrm{NaHCO}_{3}, 1.25 \mathrm{KH}_{2} \mathrm{PO}_{4}$, and $20 \mathrm{D}$-glucose, was oxygenated with a gas mixture of $95 \% \mathrm{O}_{2} / 5 \% \mathrm{CO}_{2}$. The hippocampal slices were transferred to a recording chamber after they were incubated in ACSF for at least one hour at $32{ }^{\circ} \mathrm{C}$ for recovery.

\section{Whole-cell Patch Clamp Recording}

All the electrophysiological recordings were performed at room temperature $\left(25 \pm 1^{\circ} \mathrm{C}\right)$. An EPC-10 amplifier (HEKA Elektronik, Lambrecht/Pfalz, Germany) was used to record and amplify $I_{k}$, sampling at $10 \mathrm{kHz}$ with a $2.9 \mathrm{kHz}$ Bessel filter. The capacitance and series resistance were compensated to $90 \%$. Hippocampal CA1 pyramidal neurons were perfused continually with oxygenated external solution composed of (in mM) $125 \mathrm{NaCl}, 2.5 \mathrm{KCl}, 1 \mathrm{CaCl}_{2}, 1 \mathrm{MgCl}_{2}, 26 \mathrm{NaHCO}_{3}, 1.25 \mathrm{KH}_{2} \mathrm{PO}_{4}$, and $20 \mathrm{D}$-glucose. To the external solution, $0.3 \mu \mathrm{M}$ tetrodotoxin (TTX), $5 \mathrm{mM}$ 4-aminopyridine (4-AP), and $1 \mathrm{mM} \mathrm{CdCl} 2$ were added to block TTX-sensitive voltage-gated sodium current, $I_{\mathrm{A}}$, and voltage-gated calcium current, respectively. The pipette solution was composed of (in $\mathrm{mM}$ ) $140 \mathrm{KCl}, 1 \mathrm{CaCl}_{2}, 2 \mathrm{MgCl}_{2}, 10 \mathrm{EGTA}, 10$ HEPES, and 5 Tris-ATP at $\mathrm{pH}$ 7.25. The voltage-dependent activation curve ( $\mathrm{G}-\mathrm{V}$ curve) curve of $l_{\mathrm{K}}$ was measured by a series of depolarizing pulses $(500 \mathrm{~ms}$ ) ranging from $-100 \mathrm{mV}$ to $+50 \mathrm{mV}$, with increments of $10 \mathrm{mV}$ after every $5 \mathrm{~s}$. The voltage-dependent inactivation curve (inactivation-voltage curve) was measured by double pulses: preconditioned pulses $(2 \mathrm{~s})$ ranging from $-120 \mathrm{mV}$ to $+50 \mathrm{mV}$, with increments of $10 \mathrm{mV}$, followed by $+50 \mathrm{mV}$ test pulse $(500 \mathrm{~ms})$ with an internal time of $5 \mathrm{~s}$. The holding potential was $-80 \mathrm{mV}$ in all experiments. The expression of TRPV4 in the hippocampal CA1 pyramidal neurons was functionally verified by examining the TRPV4 agonist-evoked current as reported previously $[8,9]$.

\section{Pise Preparation}

Male mice (eight weeks old, weighing 25-30 g) were intraperitoneally (ip.) injected with methylscopolamine $(1 \mathrm{mg} / \mathrm{kg})$ to antagonize peripheral muscarinic activity. After $30 \mathrm{~min}$, pilocarpine (300 mg/kg, ip.) was injected to induce status epilepticus (SE) [21, 22]. Seizure behavioural severity was rated using the Racine scale, as follows: category 1 , immobility and facial twitch; category 2 , head nodding; category 3 , forelimb clonus; category 4, rearing; and category 5 , rearing and falling. Mice that developed category 4-5 seizures were defined as PISE mice and were intraperitoneally injected with diazepam $(10 \mathrm{mg} / \mathrm{kg})$ to terminate SE $1 \mathrm{~h}$ after its onset. Animals that did not develop category 4-5 seizures 30 min after pilocarpine injection were excluded from subsequent parts of the study. Control 
mice were injected with the same volume of saline after the injection of methylscopolamine. Each experimental group contained nine mice.

\section{Drug Treatment}

TRPV4 agonist GSK1016790A and antagonist HC-067047 were intracerebroventricularly (icv.) injected. After the male mice (eight-week-old, weighing 25-30 g) were anesthetized with $2 \%$ chloral hydrate $(20 \mathrm{ml} / \mathrm{kg}$ ), they were placed in a stereotactic device (Kopf Instruments, Tujunga, CA). A guide cannula of 23-gauge stainless steel tubing was implanted into the right lateral ventricle $(0.3 \mathrm{~mm}$ posterior, $1.0 \mathrm{~mm}$ lateral, and $2.5 \mathrm{~mm}$ ventral to bregma) and anchored to the skull with stainless steel screws and dental cement. GSK1016790A or HC-067047 was injected using a 26-gauge stainless steel needle (Plastics One, Roanoke, VA) at a rate of $0.2 \mu \mathrm{l} / \mathrm{min}$ with the help of a stepper motor-controlled microsyringe (Stoelting, Wood Dale, IL, USA). GSK1016790A and HC-067047 were first dissolved in dimethyl sulphoxide (DMSO) and then in $0.9 \%$ saline to obtain a final volume of $2 \mu$ with a DMSO concentration $<0.1 \%$. GSK $1016790 \mathrm{~A}$ ( $1 \mu \mathrm{M} /$ mouse) or HC-067047 (10 $\mu \mathrm{M} /$ mouse) was injected once daily for 3 consecutive days. To block TRPV4 in PISE mice, HC-067047 was injected $1 \mathrm{~h}$ after SE was terminated and then injected once daily for $3 \mathrm{~d}$. The doses of GSK1016790A and HC-067047 were chosen as reported previously [21, 22]. Control mice were administered an equal volume of vehicle. Each experimental group contained 9 mice.

\section{Western blot}

Hippocampi were quickly collected $3 \mathrm{~d}$ after the onset of SE or $8 \mathrm{~h}$ after the last injection of GSK1016790A or HC-067047. Subsequently, the hippocampi were homogenized in a lysis buffer containing $50 \mathrm{mM}$ Tris- $\mathrm{HCl}$ ( $\mathrm{pH}$ = 7.5), $150 \mathrm{mM} \mathrm{NaCl}, 5 \mathrm{mM}$ EDTA, $10 \mathrm{mM} \mathrm{NaF}, 1 \mathrm{mM}$ sodium orthovanadate, $1 \%$ Triton $\mathrm{X}-100,0.5 \%$ sodium deoxycholate, $1 \mathrm{mM}$ phenylmethylsulphonyl fluoride, and a protease inhibitor cocktail (Complete; Roche, Mannheim, Germany). Protein concentrations were determined using a bicinchoninic acid (BCA) Protein Assay Kit (Pierce, Rochford, IL, USA). Total proteins $(20 \mu \mathrm{g})$ were separated by sodium dodecyl sulphate polyacrylamide gel electrophoresis (SDS-PAGE) and were then transferred to a polyvinylidene difluoride (PVDF) membrane. The membrane was incubated with 5\% nonfat dry milk in Tris-buffered saline/0.1\% Tween 20 (TBST) for $1 \mathrm{~h}$ at room temperature and was then incubated with anti-Kv1.1 (Cat: APC-009, 1:200, Alomone Labs, Jerusalem, Israel), anti-Kv1.2 (Cat: APC-010, 1:200, Alomone Labs, Jerusalem, Israel), anti-Kv2.1 (Cat: 75 - 014, 1:200, UC Davis/NIH NeuroMab Facility, Davis, CA, USA), or anti-glyceraldehyde 3-phosphate dehydrogenase (anti-GAPDH) antibodies (Cat: ab181602, 1:5000; Abcam, Cambridge, UK) at $4{ }^{\circ} \mathrm{C}$ overnight. Subsequently, the membranes were washed thrice with TBST, incubated with a horseradish peroxidase (HRP)-labelled secondary antibody, and developed using an ECL detection Kit (Amersham Biosciences, Piscataway, NJ). Western blot bands were analyzed with ImageJ software (National Institutes of Health). Hippocampal samples collected from 3 mice were considered a set for Western blot analysis, and the summarized data represent the average of 3 experimental sets.

\section{Data analysis}


Data are expressed as the means \pm SEM and were analyzed with Stata 7.0 software (STATA Corporation, College Station, Texas, USA). t-test or analysis of variance (ANOVA) followed by Bonferroni's post hoc test was used for statistical analysis, and significance levels were set at $P<0.05$ and $P<0.01$. In this study, $I_{\mathrm{K}}$ were collected from neurons in which both $l_{\mathrm{K}}$ and TRPV4 agonist-evoked current could be recorded. $I_{\mathrm{K}}$ was measured at the peak outward current. G-V curves and inactivation-voltage curves were fitted by Boltzmann functions, in which $G / G_{\max }=1 /\left(1+\exp \left(V_{0.5}-V_{m}\right) / k\right)$ or $I / I_{\max }=1 /\left(1+\exp \left(V_{0.5}-V_{m}\right) / k\right)$.

$\mathrm{V}_{0.5}$ was membrane potential $\left(\mathrm{V}_{\mathrm{m}}\right)$ at which $50 \%$ of activation or inactivation was observed and $k$ was the slope of the function. The dose-response curve for the effect of GSK1016790A on $l_{K}$ was fitted by logistic equation, in which $I=I_{\max } /\left[1+\left(\mathrm{IC}_{50} / C\right)^{\eta}\right]$, where $n=$ Hill coefficient and $\mathrm{IC}_{50}=$ concentration at which $50 \%$ inhibition occurs. The protein levels of Kv1.1, Kv1.2, and Kv2.1 in the mice injected with GSK1016790A or HC-067047 were normalized to those in the mice injected with vehicle. The protein levels of Kv subunits post PISE were normalized to those in control mice. The protein levels of Kv subunits in vehicle-treated PISE mice and HC-067047-treated PISE mice were normalized to those in vehicle-treated control mice.

\section{Chemicals}

PKI, pilocarpine, and 5(6)-epoxy-8Z,11Z,14Z-eicosatrienoic acid (5,6-EET) were obtained from Cayman Chemicals (Ann Arbor, MI, USA). Tetrodotoxin was obtained from Enzo Life Science (Farmingdale, NY, USA). All other chemicals, unless otherwise stated, were obtained from Sigma Chemical Company. For patch clamp recording, GSK1016790A, 5,6-EET, HC-067047, RN1734, 8-bromoadenosine 3',5'-cyclic monophosphate sodium salt (8-Br-cAMP), phorbol 12-myristate 13-acetate (PMA), and bisindolylmaleimide II (BIM II) were extracellularly applied, and N-[2-(p-Bromocinnamylamino)ethyl]-5isoquinolinesulfonamide dihydrochloride (H-89), PKI, D-Sphingosine, and KN62 were added to the pipette solution. The concentrations of these drugs were chosen according to previous reports [8, 9, 24].

\section{Results}

\section{Effect of TRPV4 activation on $I_{K}$ in the hippocampal CA1 pyramidal neurons}

In this study, TRPV4 agonists GSK1016790A and 5,6-EET were used to study the effect of TRPV4 activation on $l_{k}$. When $1 \mu$ M GSK1016790A was applied, the amplitude of $l_{K}$ decreased by $38.52 \pm 3.16 \%$ from 32.25 $\pm 3.12 \mathrm{pA} / \mathrm{pF}$ to $19.39 \pm 2.12 \mathrm{pA} / \mathrm{pF}$ (paired t test, $n=25, P<0.05$ ) (Fig. $1 \mathrm{~A}$ and $1 \mathrm{~B}$ ). $I_{\mathrm{K}}$ recovered to $29.75 \pm 4.12 \mathrm{pA} / \mathrm{pF}$ when GSK1016790A was washed out. The decrease in $l_{\mathrm{K}}$ caused by GSK1016790A (0.1 $\mu \mathrm{M}$ to $10 \mu \mathrm{M})$ was dose dependent (Fig. 1B). Because $1 \mu \mathrm{M}$ GSK1016790A exhibited significant inhibition of $l_{\mathrm{K}}$, this concentration was used in the following experiments. In the presence of GSK1016790A, the G-V curve of $l_{K}$ did not shift, with $V_{0.5}$ being $16.92 \pm 2.06 \mathrm{mV}$ and $14.76 \pm 2.99 \mathrm{mV}$ 
(paired $t$ test, $n=7, P>0.05$ ) and $k$ being $18.79 \pm 3.12$ and $20.46 \pm 2.21$ (paired $t$ test, $n=7, P>0.05$ ) for control and GSK1016790A-treated values, respectively (Fig. 1D). Upon GSK1016790A treatment, the inactivation-voltage curve significantly shifted to the hyperpolarization direction; $\mathrm{V}_{0.5}$ shifted from $25.98 \pm 1.22 \mathrm{mV}$ to $-39.71 \pm 0.98 \mathrm{mV}$ (paired $\mathrm{t}$ test, $\mathrm{n}=8, P<0.01$ ) and $k$ from $-10.45 \pm 0.99$ and $-9.53 \pm$ 0.65 (paired $\mathrm{t}$ test, $\mathrm{n}=8, P>0.05$ ) (Fig. 1E).

5,6-EET, a metabolite of arachidonic acid, is known as a natural agonist of TRPV4. In this study, when $500 \mathrm{nM} 5$, 6-EET was applied, $l_{\mathrm{K}}$ decreased by $27.20 \pm 2.75 \%$ from $32.48 \pm 3.34 \mathrm{pA} / \mathrm{pF}$ to $23.51 \pm 2.19$ $\mathrm{pA} / \mathrm{pF}$ (paired t test, $\mathrm{n}=12, P<0.01$ ) (Fig. $2 \mathrm{~A}$ and $2 \mathrm{~B}$ ) and recovered to $28.82 \pm 4.44 \mathrm{pA} / \mathrm{pF}$ after washout. Similar to the effect of GSK1016790A, in the presence of 5,6-EET, the inactivation-voltage curve of $l_{K}$ shifted to the hyperpolarization direction (paired $t$ test, $n=8, P<0.05$ ) with the $G-V$ curve being unchanged (paired $t$ test, $\mathrm{n}=8, P>0.05$ ) (Fig. 2D and 2E).

Subsequently, TRPV4 specific antagonists HC-067047 and RN1734 were used to further confirm the involvement of TRPV4 in the inhibition of $l_{k}$. The amplitude of $l_{k}$ was not affected by the application of either $1 \mu \mathrm{M} \mathrm{HC}-067047$ ( $n=8$; control: $32.00 \pm 3.45$ pA/pF; HC-067047: $33.56 \pm 2.55$ pA/pF, paired t test, $n$ $=8, P>0.05$ ) or $10 \mu \mathrm{M}$ RN1734 (control: $32.72 \pm 2.89 \mathrm{pA} / \mathrm{pF}$, RN1734: $29.21 \pm 2.60 \mathrm{pA} / \mathrm{pF}$, paired $\mathrm{t}$ test, $\mathrm{n}=$ $8, P>0.05)$. After pre-application of HC-067047 and RN1734, GSK1016790A decreased $l_{K}$ by $5.04 \pm 2.71 \%$ and $2.96 \pm 4.19 \%$, respectively (Fig. 3C and 3D). In the presence of HC-067047 and RN1734, 5,6-EET decreased $l_{K}$ by $1.84 \pm 0.97 \%$ and $1.67 \pm 1.41 \%$, respectively (Fig. 3C and 3D). Collectively, the above results indicate that the activation of TRPV4 inhibits $l_{K}$ in the hippocampal neurons.

\section{Involvement of intracellular signalling pathways in TRPV4- induced inhibition of $I_{K}$}

The activity of VGPCs is modulated by protein kinases that are linked to intracellular signalling systems [25]. In this study, application of a protein kinase A (PKA) agonist, 8-Br-cAMP (1 mM), decreased $l_{\mathrm{K}}$ by $14.56 \pm 2.67 \%$ from $33.61 \pm 2.89 \mathrm{pA} / \mathrm{pF}$ to $28.17 \pm 2.70 \mathrm{pA} / \mathrm{pF}$ (paired $t$ test, $n=7, P<0.05$ ), and in the presence of PKA antagonist $\mathrm{H}-89(10 \mu \mathrm{M})$ and PKI $(10 \mu \mathrm{M})$, $l_{K}$ increased from $31.79 \pm 2.17 \mathrm{pA} / \mathrm{pF}$ to $37.89 \pm 1.03 \mathrm{pA} / \mathrm{pF}$ (paired t test, $n=12, P<0.01$ ) and from $32.03 \pm 2.81 \mathrm{pA} / \mathrm{pF}$ to $39.77 \pm 2.06 \mathrm{pA} / \mathrm{pF}$ (paired $t$ test, $n=12, P<0.01$ ), respectively. As shown in Fig. 4a, after pre-application of $\mathrm{H}-89$ or $\mathrm{PKI}$, GSK1016790A decreased $l_{K}$ by $35.98 \pm 1.76 \%$ and $37.09 \pm 5.48 \%$, respectively, which is not significantly different from the inhibition caused by GSK1016790A alone (unpaired t test, $P>0.05$ in each case) (Fig. 4A).

In the presence of protein kinase $C(P K C)$ agonist PMA $(1 \mathrm{mM}), l_{\mathrm{K}}$ decreased from $32.57 \pm 1.60 \mathrm{pA} / \mathrm{pF}$ to $26.10 \pm 1.98 \mathrm{pA} / \mathrm{pF}(n=7$, paired t test, $P<0.05)$, and application of PKC antagonist BIM II $(1 \mu \mathrm{M})$ and $\mathrm{D}$ sphingosine $(20 \mu \mathrm{M})$ increased $l_{K}$ from $31.18 \pm 2.08 \mathrm{pA} / \mathrm{pF}$ to $38.11 \pm 2.14 \mathrm{pA} / \mathrm{pF}$ (paired t test, $n=7, P<$ 
0.01 ) and from $32.56 \pm 1.99 \mathrm{pA} / \mathrm{pF}$ to $38.83 \pm 1.63 \mathrm{pA} / \mathrm{pF}$ (paired t test, $n=9, P<0.01$ ), respectively. As shown in Fig. 4B, neither BIM II nor D-sphingosine affected GSK1016790A-induced inhibition of $l_{\mathrm{K}}$.

VGPCs have been reported to be modulated by $\mathrm{Ca}^{2+} / \mathrm{calmodulin}^{-d e p e n d e n t ~ p r o t e i n ~ k i n a s e ~ I I ~(C a M K I I) ~}$ [26]. In this study, in the presence of CaMKII antagonist KN62 (5 $\mu \mathrm{M})$, $l_{K}$ increased from $33.18 \pm 1.55$ $\mathrm{pA} / \mathrm{pF}$ to $41.41 \pm 3.71 \mathrm{pA} / \mathrm{pF}$ (paired $t$ test, $n=10, P<0.01$ ). After pre-application of KN62, GSK1016790A decreased $l_{\mathrm{K}}$ by $10.52 \pm 2.93 \%$, which was significantly different from that caused by GSK1016790A alone (unpaired $\mathrm{t}$ test, $\mathrm{n}=33, P<0.01$ ) (Fig. 4C).

\section{Effect Of Trpv4 Activation On Kv Subunit Protein Levels}

To examine whether TRPV4 activation could affect the Kv subunit expression, Kv1.1, Kv1.2, and Kv2.1 protein levels were examined after GSK1016790A treatment. We first examined these three Kv subunit protein levels when TRPV4 was acutely activated. As shown in Fig. 5, after the hippocampal slices were perfused with GSK1016790A for $30 \mathrm{~min}$ (Fig. 5A) and $1 \mathrm{~h}$ (Fig. 5B), the protein levels of Kv1.1, Kv1.2, or Kv2.1 did not change markedly. Subsequently, we examined the protein levels of Kv subunits when TRPV4 was persistently activated. When the mice were injected (icv.) with GSK1016790A for three days, the hippocampal protein levels of Kv1.2 and Kv2.1 decreased markedly, whereas that of Kv1.1 did not change (Fig. 5c).

\section{Changes In Kv Subunit Protein Levels Post Pise}

We finally examined the protein levels of Kv1.1, Kv1.2, and Kv2.1 in PISE mice. As shown in Fig. 6, the protein levels of Kv1.2 and Kv2.1 decreased markedly post PISE and that of Kv1.1 did not change significantly. Icv. injection of HC-067047 did not change the protein level of Kv1.2, Kv2.1, and Kv1.1 in the hippocampi of control mice. When the mice were injected with TRPV4 antagonist HC-067047, the protein levels of Kv1.2 and Kv2.1 did not change significantly post PISE.

\section{Discussion}

VGPCs include a large group of potassium channels which are important regulators of intrinsic neuronal excitability [1, 2]. In the hippocampal neurons, the delayed rectifier $\mathrm{Kv}$ channels participate in regulating the action potential waveform, and inhibition of these channels accounts for broadening action potential duration and a higher instantaneous action potential firing frequency [2]. Activation of TRPV4 induces inward current, and in the hippocampus, TRPV4 has been proven to participate in modulating resting membrane potential and neuronal excitability [7]. Besides the inward current mediated by TRPV4 per se, activation of TRPV4 may affect the balance of neurotransmitter system function by modulating glutamate receptor, $Y$-aminobutyric acid receptor, and glycine receptor functions $[8,9,24]$. In the trigeminal ganglion neurons, activation of TRPV4 by hypotonic stimuli modulated $I_{A}$ and $l_{K}$ differently [13]. In the 
present study, application of TRPV4 agonists GSK1016790A and 5,6,-EET markedly decreased $l_{\mathrm{K}}$ in the hippocampal neurons (Figs. 1 and 2), and these effect were significantly blocked by TRPV4-specific antagonists HC-067047 and RN1734 (Fig. 3), indicating that delayed rectifier Kv channels in the hippocampal neurons could be inhibited by the activation of TRPV4. We also found that the application of the TRPV4 agonist had no effect on the $G-V$ curve of $l_{k}$, but it markedly shifted the inactivationvoltage curve to the hyperpolarization direction (Fig. 1D and 1E, Fig. 2D and 2E). This result indicated that the decrease in $l_{k}$ caused by TRPV4 activation may be a result of acceleration of channel inactivation.

Phosphorylation is the most common posttranslational modification undergone by eukaryotic proteins. Phosphorylation by protein kinases allows a fast modulation of VGPCs activity, which could modify the neuronal firing pattern and response to synaptic inputs. It has become apparent that VGPCs can be phosphorylated by PKA, PKC, and CaMKII signalling pathways $[25,26]$. Whole $\mathrm{K}^{+}$current in cultured neurons of murine colliculi and $l_{K}$ in the trigeminal ganglion neurons have been reported to be inhibited by cAMP-dependent PKA activation $[13,27]$. Similarly, in the present study, $l_{K}$ recorded in the hippocampal neurons was inhibited by the activation of PKA. Application of the PKC agonist PMA increased the cloned human slowly activating delayed rectifier $\mathrm{K}^{+}$current in HEK293 cells, but the PKC $\varepsilon$ peptide activator inhibited the current [28]. Some reports suggest that $l_{K}$ is inhibited by the activation of PKC in rat parietal cortical neurons and trigeminal ganglion neurons and juvenile guinea pig isolated hippocampal neurons $[13,29,30]$. The present study found that the activation of PKC inhibited $l_{K}$ in the hippocampal neurons. In previous studies, the PKA and PKC signalling pathways have been involved in the TRPV4-induced modulation of voltage-gated sodium, a- amino-3-hydroxy-5-methyl-4-isoxazolpropionic acid glutamate receptor, or TRPV1 [31, 32, 33]. In this study, blockage of PKA or PKC did not attenuate GSK1016790Ainduced inhibition of $l_{K}$ (Fig. 4A and 4B), indicating that neither PKA nor PKC is responsible for TRPV4 activation-induced inhibition of $l_{k}$.

Evidence suggests that CaMKII plays a role in the modulation of VGPCs function. In the trigeminal ganglion neurons, VGPCs were inhibited by a CaMKII antagonist KN-93 and the inhibition of $l_{\mathrm{K}}$ was more evident than that of $I_{A}$ [34]. Application of CaMKII inhibitory peptide or CaMKII antagonist KN-93 inhibited $I_{K}$ in the cultured hypothalamus and brain stem neurons [26]. Activation of TRPV4 could elevate intracellular calcium concentration in the hippocampal neurons [12]. In osteocytes, CaMKII was activated by TRPV4-mediated $\mathrm{Ca}^{2+}$ influx [35]. CaMKII has been proven to participate in TRPV4-induced modulation of $\mathrm{N}$-methyl-D-aspartate glutamate receptor and glycine receptor in the hippocampal neurons as well as voltage-gated sodium current in the ventricular myocytes [9, 24, 36]. It has been reported that the application of KN-93 inhibited a wide range of Kv channels in HEK 293 cells and that this effect was independent of CaMKII [37]. Therefore, in the present study, another CaMKII antagonist KN-62 was used to examine the role of CaMKII in TRPV4 activation-inhibited $l_{\mathrm{K}}$. It was found that pre-application of KN-62 markedly blocked GSK1016790A-induced inhibition of $l_{K}$ (Fig. 4C), indicating that CaMKII was responsible, at least in part, for the inhibition of $l_{\mathrm{K}}$ caused by TRPV4 activation. 
VGPCs are likely the most diverse class of voltage-gated ion channels. In humans, VGPCs are encoded by 40 different genes and categorized into 12 subfamilies. The present study mainly examined the changes in expression of Kv1.1, Kv1.2, and Kv2.1 as they are the main components contributing to $I_{K}$ in the hippocampus [3, 4, 5]. In the present study, the protein levels of Kv1.1, Kv1.2, and Kv2.1 did not change upon the application of GSK1016790A for 30 min or $1 \mathrm{~h}$, indicating that the expression of these three Kv subunits was not affected by acute TRPV4 activation (Fig. 5A and 5B). The inhibition of $l_{K}$ is unlikely due to the decrease in the expression of these three Kv subunits. Previous studies showed that when TRPV4 is chronically or persistently activated, the expression of ion channels and receptors may change [24]. In this study, the hippocampal expression levels of Kv1.2 and Kv2.1 decreased markedly when the mice were injected with GSK1016790A for 3 days (Fig. 5C). Therefore, it is indicated that when TRPV4 is persistently activated, the decreased expression of Kv1.2 and Kv2.1 may contribute to the inhibition of $l_{\mathrm{K}}$.

Epilepsy is a common neurological disorder characterized by recurrent seizures. As VGPCs play important roles in setting the resting membrane potential, repolarizing neurons following APs, and controlling the firing patterns, the neuronal channelopathy of VGPCs has been found to be involved in the pathogenesis of different types of epilepsy. Mice lacking the Kv1.1 a subunit encoded by the KCNA1 gene develop recurrent behavioural seizures early in life [19]. Epilepsy gene therapy targeting KCNA1 suppresses seizures in TLE rat models [38]. Inhibition of Kv1.1 channels inactivation reduces neuronal excitability and epileptiform activity [39]. Decreasing the expression of Kv1.2 channels enhances intrinsic excitability to cause epilepsy [40]. Mutation of $K C N B 1$ resulting in the loss of Kv2.1 ion selectivity leads to the development of epilepsy [41]. There is evidence that TRPV4 is likely involved in the pathogenesis of epilepsy. The expression of TRPV4 increased in TLE mice, and blockage of TRPV4 markedly blocked the changes in connexion 43 and neuronal death in TLE mice [21, 22]. Altered expressions of Kv4.2, the largeconductance $\mathrm{Ca}$-activated $\mathrm{K}$ channels, and the small-conductance $\mathrm{Ca}$-activated $\mathrm{K}$ channels have been reported in pilocarpine model of TLE $[42,43,44]$. The present study showed that the hippocampal protein levels of Kv1.2 and Kv2.1 reduced post PISE and that this change could be attenuated by TRPV4 antagonist, which indicates the role of TRPV4 in this process (Fig. 6). More research is needed to clarify the mechanisms underlying TRPV4-involved in the pathogenesis of TLE.

\section{Conclusion}

In summary, the present study showed that the activation of TRPV4 could inhibit $l_{K}$ in hippocampal pyramidal neurons, which may slow down the repolarization of the AP, thus providing a basis for a higher AP firing frequency. The inhibition of $l_{K}$ may provide more evidence for the mechanisms underlying TRPV4 activation-increased neuronal excitability in the hippocampus. Activation of TRPV4 decreased the expression of Kv1.2 and Kv2.1, which may be involved in changes in Kv subunits post PISE. This modulation of Kv subunits expression helps us to better understand the role of TRPV4 in the pathological process of TLE. VGPCs include the largest and most diverse family of genes, and whether the activation of TRPV4 could modulate other subtypes of VGPCs remains to be studied further. 


\section{Abbreviations}

APs: action potentials; BCA: bicinchoninic acid; BIM II: bisindolylmaleimide Il; $\mathrm{Ca}^{2+}$ : calcium; CaMKII:

$\mathrm{Ca}^{2+} /$ calmodulin-dependent protein kinase II; DMSO: dimethyl sulphoxide; 8-Br-CAMP: 8-bromoadenosine 3',5'-cyclic monophosphate sodium salt; 5,6-EET: 5(6)-epoxy-8Z,11Z,14Z-eicosatrienoic acid; 4-AP: 4aminopyridine; GAPDH: glyceraldehyde 3-phosphate dehydrogenase; G-V curve: voltage-dependent activation curve; $\mathrm{H}-89$ : $\mathrm{N}$-[2-(p-Bromocinnamylamino)ethyl]-5-isoquinolinesulfonamide dihydrochloride; HRP: horseradish peroxidise; $I_{A}$ : fast transient potassium current; icv.: intracerebroventricularly; inactivation-voltage curve: voltage-dependent inactivation curve; $l_{k}$ : delayed rectifier potassium current; ip.: intraperitoneally; PISE: pilocarpine-induced status epilepticus; PKA: protein kinase A; PKC: protein kinase C; PMA: phorbol 12-myristate 13-acetate; PVDF: polyvinylidene difluoride; SE: status epilepticus; SDS-PAGE: sodium dodecyl sulphate polyacrylamide gel electrophoresis; TBST: Tris-buffered saline/ $0.1 \%$ Tween 20; TLE: temporal lobe epilepsy; TRPV4: transient receptor potential vanilloid 4; TTX: tetrodotoxin; VGPCs: voltage-gated potassium channels

\section{Declarations}

\section{Ethics Approval And Consent To Participate}

All the animal experiments were carried out in accordance with the National Institute of Health Guide for the Care and Use of Laboratory Animals (NIH Publications No. 80 - 23) revised in 1996 and approved by the Ethics Committee of Nanjing Medical University (No. IACUC-1811044). All efforts were made to minimize animal suffering and to reduce the number of animals used.

\section{Consent For Publication}

Not applicable.

\section{Competing interests}

The authors declare that they have no competing interests.

\section{Funding}

This work was supported by National Natural Science Foundation of China (81971274 and 81571270 ) and 13th Talents Project of Jiangsu Province (JY-049) to Lei Chen; National Natural Science Foundation of China (81770328) to Yimei Du.

\section{Authors' contributions}


LC designed the study and wrote the manuscript. LZ, WX and DA performed the experiments. LZ performed whole patch clamp recordings, WX performed western blot analyses, and DA prepared PISE mice and performed the icv. injection. $C M$ and $Y L$ did the data analysis. YD helped to revise the manuscript. All authors approved the manuscript.

\section{Acknowledgements}

Not applicable.

\section{Availability of data and materials}

The datasets analyzed during the current study available from the corresponding author upon request.

\section{References}

1. Pongs 0 . Voltage-gated potassium channels: from hyperexcitability to excitement. FEBS Lett. 1999;452:31-5. doi:10.1016/s0014-5793(99)00535-9.

2. Klee R, Ficker E, Heinemann U. Comparison of voltage-dependent potassium currents in rat pyramidal neurons acutely isolated from hippocampal regions CA1 and CA3. J Neurophysiol. 1995;74:198295. doi:10.1152/jn.1995.74.5.1982.

3. Antonucci DE, Lim ST, Vassanelli S, Trimmer JS. Dynamic localization and clustering of dendritic Kv2.1 voltage-dependent potassium channels in developing hippocampal neurons. Neuroscience. 2001;108:69-81. doi:10.1016/s0306-4522(01)00476-6.

4. Monaghan MM, Trimmer JS, Rhodes KJ. Experimental localization of Kv1 family voltage-gated K + channel alpha and beta subunits in rat hippocampal formation. J Neurosci. 2001;21:5973-83. doi:10.1523/jneurosci.21-16-05973.2001.

5. Ranjan R, Logette E, Marani M, Herzog M, Tâche V, Scantamburlo E, et al. A Kinetic Map of the Homomeric Voltage-Gated Potassium Channel (Kv) Family. Front Cell Neurosci. 2019;13:358. doi:10.3389/fncel.2019.00358.

6. Maljevic S, Lerche $\mathrm{H}$. Potassium channels: a review of broadening therapeutic possibilities for neurological diseases. J Neurol. 2012;260:2201-11. doi:10.1007/s00415-012-6727-8.

7. White JP, Cibelli M, Urban L, Nilius B, McGeown JG, Nagy I. TRPV4: Molecular Conductor of a Diverse Orchestra. Physiol Rev. 2016;96:911-73.

8. Hong Z, Tian Y, Qi M, Li Y, Du Y, Chen L, et al. Transient Receptor Potential Vanilloid 4 Inhibits YAminobutyric Acid-Activated Current in Hippocampal Pyramidal Neurons. Front Mol Neurosci. 2016;9:77. 10.3389/fnmol.2016.00077. doi .

9. Li L, Qu W, Zhou L, Lu Z, Jie P, Chen L, et al. Activation of transient receptor potential vanilloid 4 increases NMDA-activated current in hippocampal pyramidal neurons. Front Cell Neurosci. 
2013;7:17. doi:10.3389/fncel.2013.00017.

10. Ryskamp DA, Witkovsky P, Barabas $P$, Huang W, Koehler C, Akimov NP, et al. The polymodal ion channel transient receptor potential vanilloid 4 modulates calcium flux, spiking rate, and apoptosis of mouse retinal ganglion cells. J Neurosci. 2011;31:7089-101. doi:10.1523/JNEUROSCI.035911.2011.

11. Shibasaki K, Ikenaka K, Tamalu F, Tominaga M, Ishizaki Y. A novel subtype of astrocytes expressing TRPV4 (transient receptor potential vanilloid 4) regulates neuronal excitability via release of gliotransmitters. J Biol Chem. 2014;289:14470-80. doi:10.1074/jbc.M114.557132.

12. Shibasaki K, Suzuki M, Mizuno A, Tominaga M. Effects of body temperature on neural activity in the hippocampus: regulation of resting membrane potentials by transient receptor potential vanilloid $4 . \mathrm{J}$ Neurosci. 2007;27:1566-75. doi:10.1523/JNEUROSCl.4284-06.2007.

13. Chen L, Liu C, Liu L. The modulation of voltage-gated potassium channels by anisotonicity in trigeminal ganglion neurons. Neuroscience. 2008;154:482-95.

doi:10.1016/j.neuroscience.2008.03.046.

14. Earley S. Endothelium-dependent cerebral artery dilation mediated by transient receptor potential and Ca2+-activated K + channels. J Cardiovasc Pharmacol. 2011;57:148-53.

doi:10.1097/FJC.0b013e3181f580d9.

15. Naik JS, Osmond JM, Walker BR, Kanagy NL. Hydrogen sulfide-induced vasodilation mediated by endothelial TRPV4 channels. Am J Physiol Heart Circ Physiol. 2016;311:H1437-44. doi:10.1152/ajpheart.00465.2016.

16. Duncan JS, Sander JW, Sisodiya SM, Walker MC. Adult epilepsy. Lancet. 2006;367:1087-100. doi:10.1016/S0140-6736(06)68477-8.

17. Lerche $H$, Jurkat-Rott K, Lehmann-Horn F. Ion channels and epilepsy. Am J Med Genet. 2001;106:146-59. doi:10.1002/ajmg.1582.

18. Wei F, Yan LM, Su T, He N, Lin ZJ, Wang J, et al. Ion Channel Genes and Epilepsy: Functional Alteration, Pathogenic Potential, and Mechanism of Epilepsy. Neurosci Bull. 2017;33:455-77. doi:10.1007/s12264-017-0134-1.

19. Wenzel HJ, Vacher H, Clark E, Trimmer JS, Lee AL, Sapolsky RM, et al. Structural consequences of Kcna1 gene deletion and transfer in the mouse hippocampus. Epilepsia. 2007;48:2023-46. doi:10.1111/j.1528-1167.2007.01189.x.

20. Schulte U, Thumfart JO, Klöcker N, Sailer CA, Bildl W, Biniossek M, et al. The epilepsy-linked Lgi1 protein assembles into presynaptic Kv1 channels and inhibits inactivation by Kvbeta1. Neuron. 2006;49:697-706. doi:10.1016/j.neuron.2006.01.033.

21. Men C, Wang Z, Zhou L, Qi M, An D, Xu W, et al. Transient receptor potential vanilloid 4 is involved in the upregulation of connexin expression following pilocarpine-induced status epilepticus in mice. Brain Res Bull. 2019;152:128-33. doi:10.1016/j.brainresbull.2019.07.004.

22. Wang Z, Zhou L, An D, Xu W, Wu C, Sha S, et al. TRPV4-induced inflammatory response is involved in neuronal death in pilocarpine model of temporal lobe epilepsy in mice. Cell Death Dis. 2019;10:386. 
doi:10.1038/s41419-019-1612-3.

23. Hunt RF, Hortopan GA, Gillespie A, Baraban SC. A novel zebrafish model of hyperthermia-induced seizures reveals a role for TRPV4 channels and NMDA-type glutamate receptors. Exp Neurol. 2012;237:199-206. doi:10.1016/j.expneurol.2012.06.013.

24. Qi M, Wu C, Wang Z, Zhou L, Men C, Du Y, et al. Transient receptor potential vanilloid 4 activationinduced increase in glycine-activated current in mouse hippocampal pyramidal neurons. Cell Physiol Biochem. 2018;45:1084-96. doi:10.1159/000487350.

25. Jonas EA, Kaczmarek LK. Regulation of potassium channels by protein kinases. Curr Opin Neurobiol. 1996;6:318-23. doi:10.1016/s0959-4388(96)80114-0.

26. Zhu M, Gelband CH, Posner P, Sumners C. Angiotensin II decreases neuronal delayed rectifier potassium current: role of calcium/calmodulin-dependent protein kinase II. J Neurophysiol. 1999;82:1560-8. doi:10.1152/jn.1999.82.3.1560.

27. Fagni L, Dumuis A, Sebben M, Bockaert J. The 5-HT4 receptor subtype inhibits $K+$ current in colliculi neurones via activation of a cyclic AMP-dependent protein kinase. Br J Pharmacol. 1992;105:97379. doi:10.1111/j.1476-5381.1992.tb09087.x.

28. Gou X, Wang W, Zou S, Qi Y, Xu Y. Protein kinase C epsilon mediates the inhibition of angiotensin II on the slowly activating delayed-rectifier potassium current through channel phosphorylation. $\mathrm{J}$ Mol Cell Cardiol. 2018;116:165-74. doi:10.1016/j.yjmcc.2018.02.010.

29. Song CY, Xi HJ, Yang L, Qu LH, Yue ZY, Zhou J, et al. Propofol inhibited the delayed rectifier potassium current $(I(k))$ via activation of protein kinase $C$ epsilon in rat parietal cortical neurons. Eur J Pharmacol. 2018;653:16-20. doi:10.1016/j.ejphar.2010.10.072.

30. Doerner D, Pitler TA, Alger BE. Protein kinase $C$ activators block specific calcium and potassium current components in isolated hippocampal neurons. J Neurosci. 1988;8:4069-78. doi:10.1523/jneurosci.08-11-04069.1988.

31. Chen L, Liu C, Liu L, Cao X. Changes in osmolality modulate voltage-gated sodium channels in trigeminal ganglion neurons. Neurosci Res. 2009;64:199-207. doi:10.1016/j.neures.2009.02.012.

32. Li L, Yin J, Jie PH, Lu ZH, Zhou LB, Chen L, et al. Transient receptor potential vanilloid 4 mediates hypotonicity-induced enhancement of synaptic transmission in hippocampal slices. CNS Neurosci Ther. 2013;19:854-62. doi:10.1111/cns.12143.

33. Liu L, Chen L, Liedtke W, Simon SA. Changes in osmolality sensitize the response to capsaicin in trigeminal sensory neurons. J Neurophysiol. 2007;97:2001-15. doi:10.1152/jn.00887.2006.

34. Liang R, Liu X, Wei L, Wang W, Zheng P, Yan X, et al. The modulation of the excitability of primary sensory neurons by $\mathrm{Ca}^{2+}-\mathrm{CaM}-\mathrm{CaMKII}$ pathway. Neurol Sci. 2012;33:1083-93. doi:10.1007/s10072011-0907-7.

35. Lyons JS, Joca HC, Law RA, Williams KM, Kerr JP, Shi G, et al. Microtubules tune mechanotransduction through NOX2 and TRPV4 to decrease sclerostin abundance in osteocytes. Sci Signal. 2017;10:eaan5748. doi:10.1126/scisignal.aan5748. 
36. Hu L, Ma J, Zhang P, Zheng J. Extracellular hypotonicity induces disturbance of sodium currents in rat ventricular myocytes. Physiol Res. 2009;58:807-15.

37. Rezazadeh S, Claydon TW, Fedida D. KN-93 (2-[N-(2-hydroxyethyl)]-N-(4methoxybenzenesulfonyl)]amino-N-(4-chlorocinnamyl)-N-methylbenzylamine), a calcium/calmodulin-dependent protein kinase II inhibitor, is a direct extracellular blocker of voltagegated potassium channels. J Pharmacol Exp Ther. 2006;317:292-9. doi:10.1124/jpet.105.097618.

38. Snowball A, Chabrol E, Wykes RC, Shekh-Ahmad T, Cornford JH, Lieb A, et al. Epilepsy gene therapy using an engineered potassium channel. J Neurosci. 2019;39:3159-69.

doi:10.1523/JNEUROSCI.1143-18.2019.

39. Niespodziany I, Mullier B, André VM, Ghisdal P, Jnoff E, Moreno-Delgado D, et al. Discovery of a small molecule modulator of the Kv1.1/Kv $\beta 1$ channel complex that reduces neuronal excitability and in vitro epileptiform activity. CNS Neurosci Ther. 2019;25:442-51. doi:10.1111/cns.13060.

40. Zhou L, Zhou L, Su LD, Cao SL, Xie YJ, Wang N, et al. Celecoxib Ameliorates Seizure Susceptibility in Autosomal Dominant Lateral Temporal Epilepsy. J Neurosci. 2018;38:3346-57. doi:10.1523/JNEUROSCI.3245-17.2018.

41. Thiffault I, Speca DJ, Austin DC, Cobb MM, Eum KS, Safina NP, et al. A novel epileptic encephalopathy mutation in KCNB1 disrupts Kv2.1 ion selectivity, expression, and localization. J Gen Physiol. 2015;146:399-410. doi:10.1085/jgp.201511444.

42. Su T, Cong WD, Long YS, Luo AH, Sun WW, Deng WY, et al. Altered expression of voltage-gated potassium channel 4.2 and voltage-gated potassium channel 4-interacting protein, and changes in intracellular calcium levels following lithium-pilocarpine-induced status epilepticus. Neuroscience. 2008;157:566-76. doi:10.1016/j.neuroscience.2008.09.027.

43. Ermolinsky BS, Skinner F, Garcia I, Arshasamanb MF, Otalora LFP, Zarei MM, et al. Upregulation of STREX splice variant of the large conductance Ca2+-activated potassium (BK) channel in a rat model of mesial temporal lobe epilepsy. Neurosci Res. 2011;69:73-80. doi:10.1016/j.neures.2010.09.011.

44. Schulz R, Kirschstein T, Brehme H, Porath K, Mikkat U, Köhling R. Altered expression and function of small-conductance (SK) $\mathrm{Ca}(2+)$-activated $\mathrm{K}+$ channels in pilocarpine-treated epileptic rats. Brain Res. 2010;1348:187-99. doi:10.1016/j.brainres.2010.05.095.

\section{Figures}


A
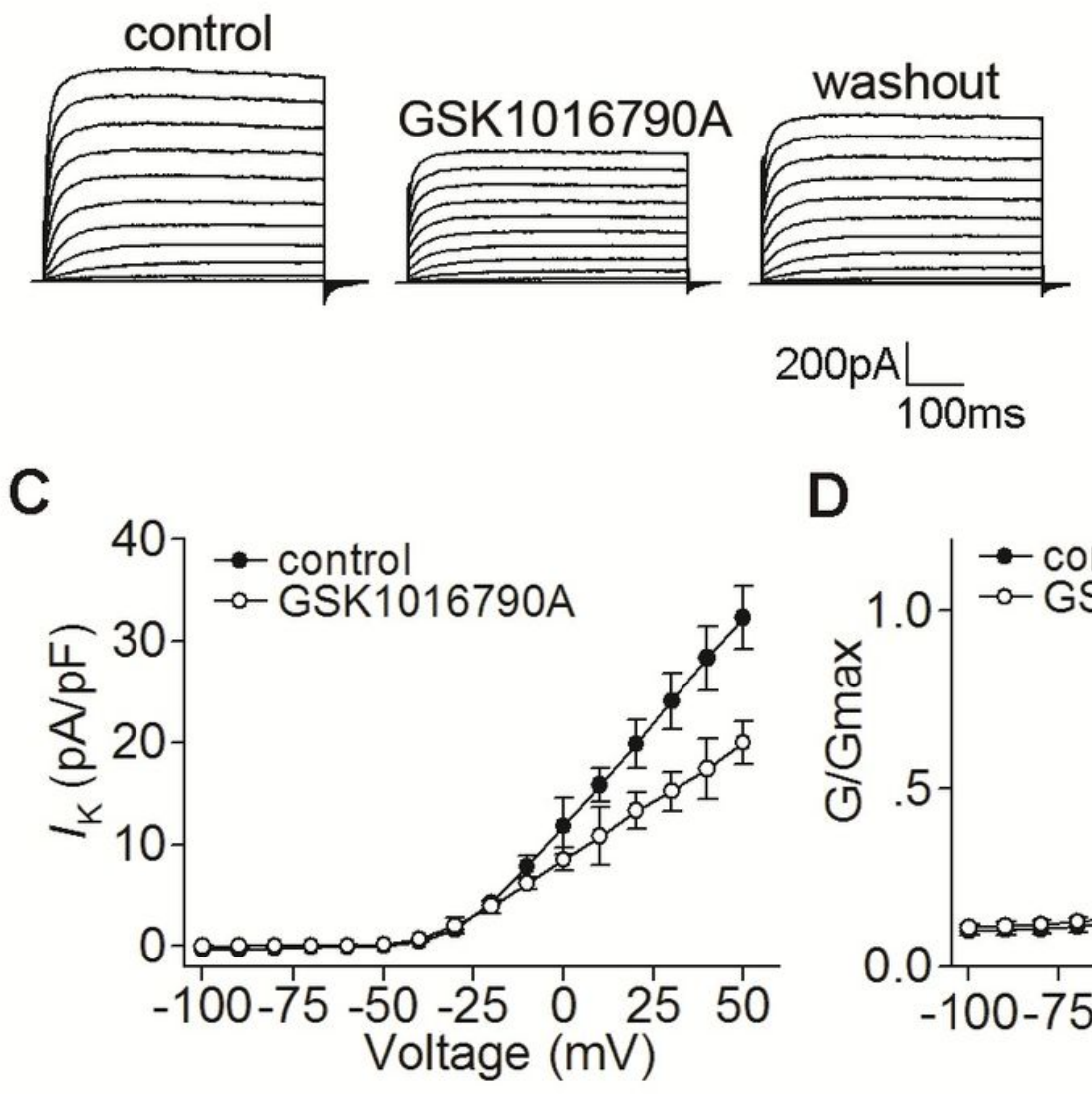

D
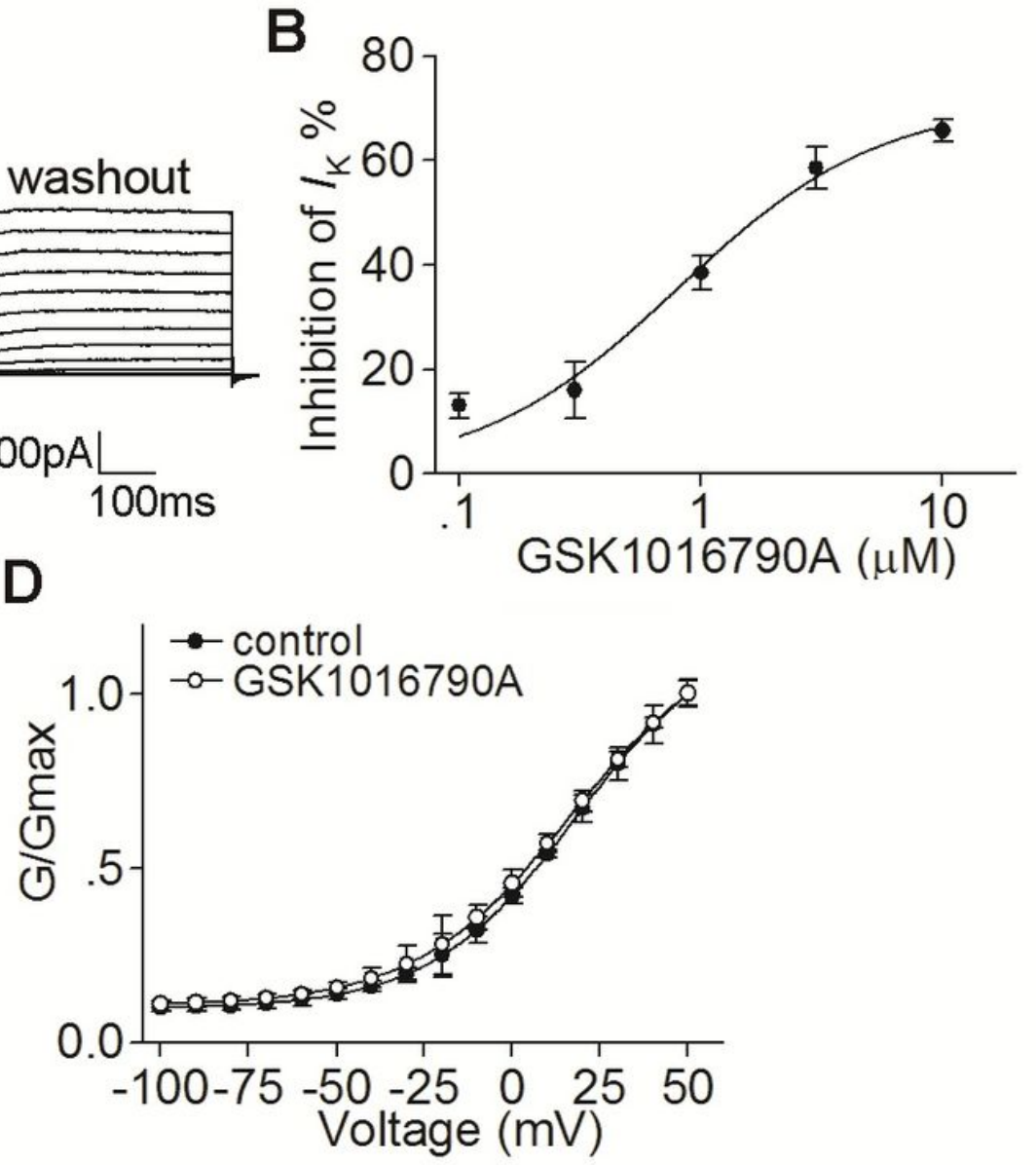

E

control
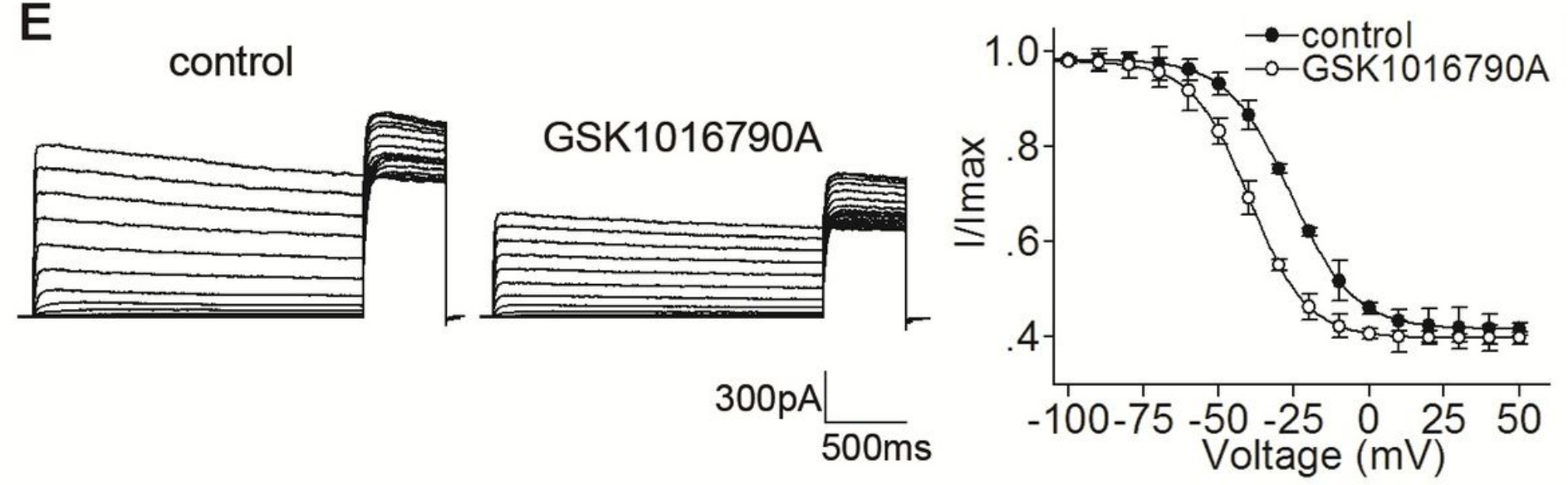

Figure 1

Effect of TRPV4 agonist GSK1016790A on IK in hippocampal neurons A. Typical recordings of IK before, during and after GSK1016790A treatment. IK was inhibited from 1.05 nA to 0.63 nA by GSK1016790A (1 $\mu \mathrm{M})$, and the current recovered to $0.91 \mathrm{nA}$ after washout. B. The dose-dependent curve of GSK1016790Ainduced inhibition of IK. Plots show the inhibition of IK by GSK1016790A at concentrations of $0.1(n=8)$, $0.3(n=9), 1(n=25), 3(n=9)$ and $10 \mu M(n=8)$. The dose-response curve is fitted to Hill equation with EC50 being $0.88 \mu \mathrm{M}$ and $\mathrm{n}$ being 1.72. C. The voltage-current relationship (I-V curve) of IK before and during GSK1016790A treatment. D. The G-V curve of IK before and during GSK1016790A treatment. 
Data were transformed from the I-V data shown in C. E. The inactivation-voltage curve of IK before and during GSK1016790A treatment. The inactivation-voltage curve markedly shifted to the hyperpoloarization direction by application of GSK1016790A.

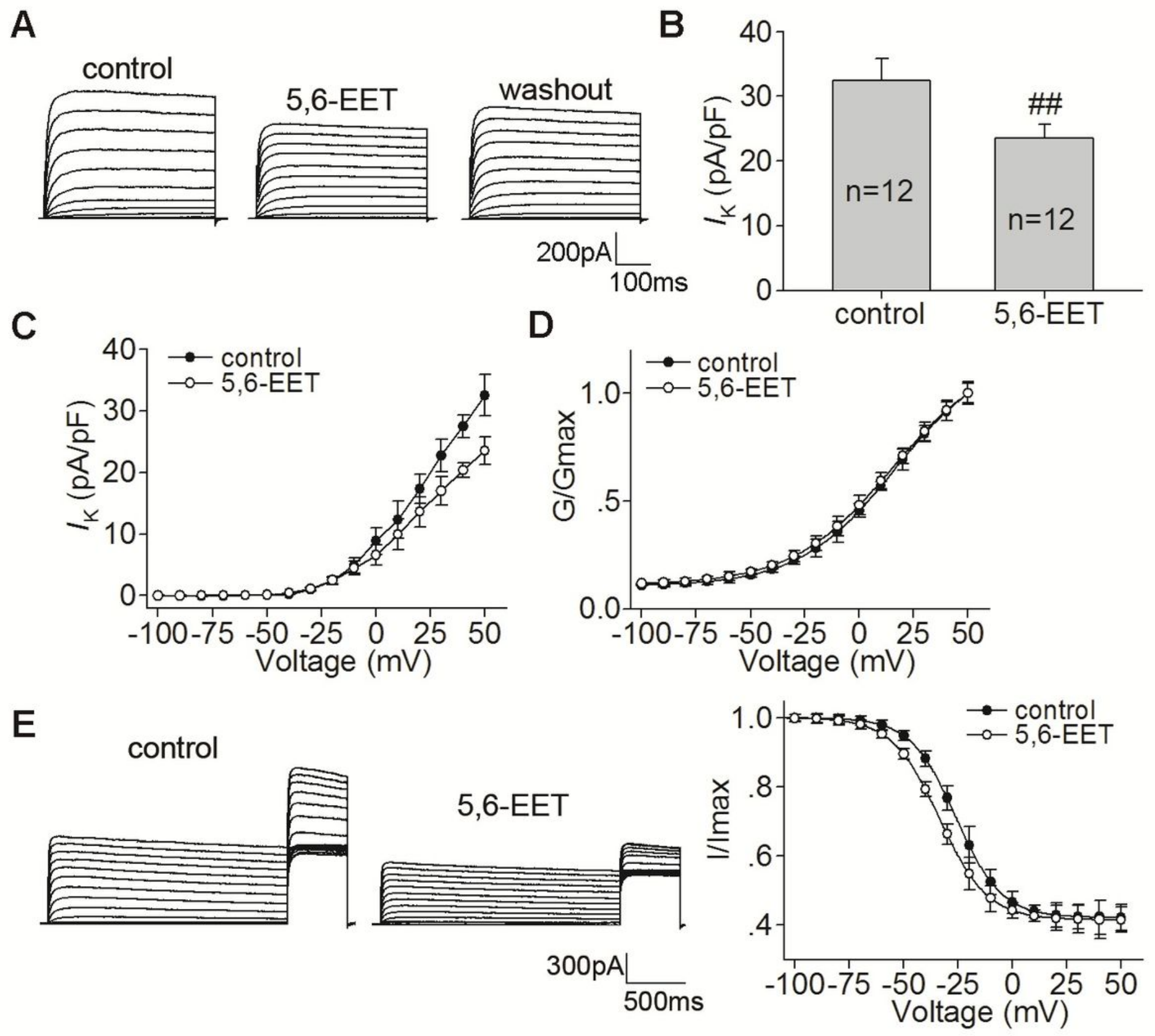

Figure 2

Effect of TRPV4 agonist 5,6-EET on IK in hippocampal pyramidal neurons $A$ and $B$. The histogram (B) and typical recordings (A) showing the effect of 5,6-EET on IK. IK was $1.09 \mathrm{nA}, 0.78 \mathrm{nA}$ and $0.91 \mathrm{nA}$ before, during and after 5,6-EET-treatment, respectively. Paired $t$ test, \#\#P<0.01 vs. control C. The I-V curve of IK before and during 5,6-EET treatment. D. The G-V curve of IK before and during 5,6-EET treatment. The G-V curve did not shift, with V0.5 (control: $16.67 \pm 0.67 \mathrm{mV} ; 5,6-\mathrm{EET}: 15.32 \pm 1.73 \mathrm{mV}$ ) and $k$ (control: $21.26 \pm 1.09 ; 5,6-E E T: 22.07 \pm 0.86$ ) being unchanged (paired $t$ test, $n=8, P>0.05$ in each 
case). Data were transformed from the I-V data shown in C. E. The inactivation-voltage curve of IK before and during 5,6-EET treatment. The inactivation-voltage curve markedly shifted to the hyperpolarization direction upon 5,6-EET treatment, with V0.5 being $-25.83 \pm 1.13 \mathrm{mV}$ and $-33.36 \pm 1.87$ $m V(n=8$, paired $t$ test, $P<0.01)$, and $k$ being $-10.38 \pm 0.79$ and $-10.93 \pm 0.98$ for control and 5,6-EET, respectively (paired $t$ test, $n=8, P>0.05$ ).

A
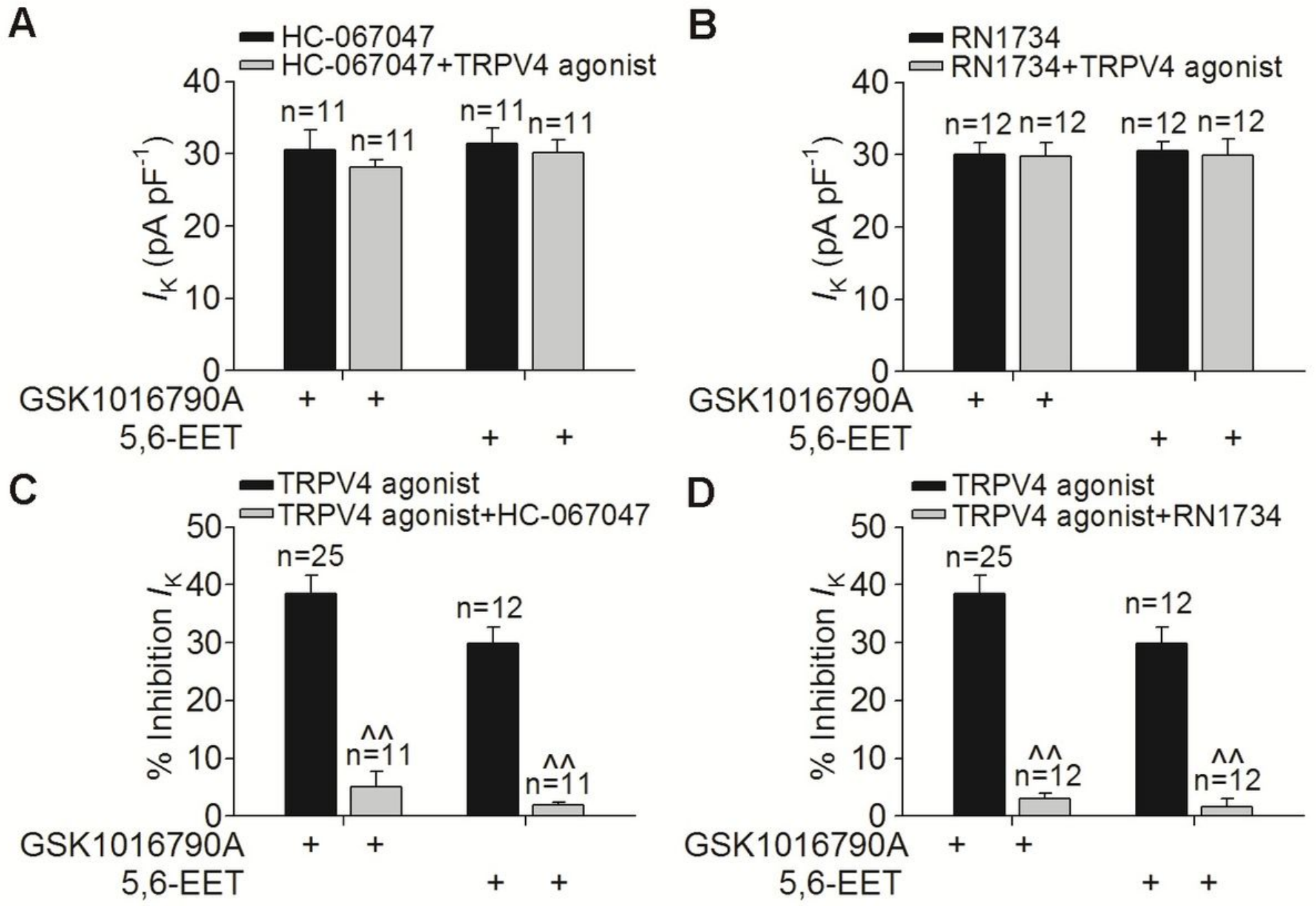

Figure 3

Effects of TRPV4 antagonists on the inhibition of IK caused by GSK1016790A and 5,6-EET A. In the presence of the TRPV4 antagonist HC-067047, IK was 30.51 $\pm 2.72 \mathrm{pA} / \mathrm{pF}$ and $28.11 \pm 1.02 \mathrm{pA} / \mathrm{pF}$ before and during GSK1016790A treatment (paired $t$ test, $n=8, P>0.05$ ), and was $31.44 \pm 2.14 p A / p F$ and $30.71 \pm 1.73 \mathrm{pA} / \mathrm{pF}$ before and during 5, 6-EET treatment (paired $t$ test, $n=7, P>0.05$ ), respectively. $B$. With TRPV4 antagonist RN1734 in the bath solution, IK was $30.01 \pm 1.64 \mathrm{pA} / \mathrm{pF}$ and $29.73 \pm 1.98 \mathrm{pA} / \mathrm{pF}$ before and during GSK1016790A treatment (paired $t$ test, $n=12, P>0.05$ ), and was 30.54 $\pm 1.19 \mathrm{pA} / \mathrm{pF}$ and 29.89 $\pm 2.35 \mathrm{pA} / \mathrm{pF}$ (paired $\mathrm{t}$ test, $\mathrm{n}=12, \mathrm{P}>0.05$ ) before and during 5, 6-EET treatment, respectively. $\mathrm{C}$. In the presence of HC-067047, the inhibition of IK by GSK1016790A reduced from $38.56 \pm 3.16 \%$ to $5.04 \pm 2.71 \%$ (unpaired $t$ test, $n=34, P<0.01$ ), and that by 5,6 -EET reduced from $29.79 \pm 2.97 \%$ to 
$1.84 \pm 0.97 \%$ (unpaired $t$ test, $n=21, P<0.01$ ) D. Pre-application of RN1734, GSK1016790A-induced inhibition of IK reduced from $38.56 \pm 3.16 \%$ to $2.96 \pm 4.19 \%$ (unpaired $t$ test, $n=34, P<0.01$ ) and $5,6-E E T$ induced inhibition reduced from $29.79 \pm 2.97 \%$ to $1.67 \pm 1.41 \%$ (unpaired $t$ test, $n=22, P<0.01$ ).

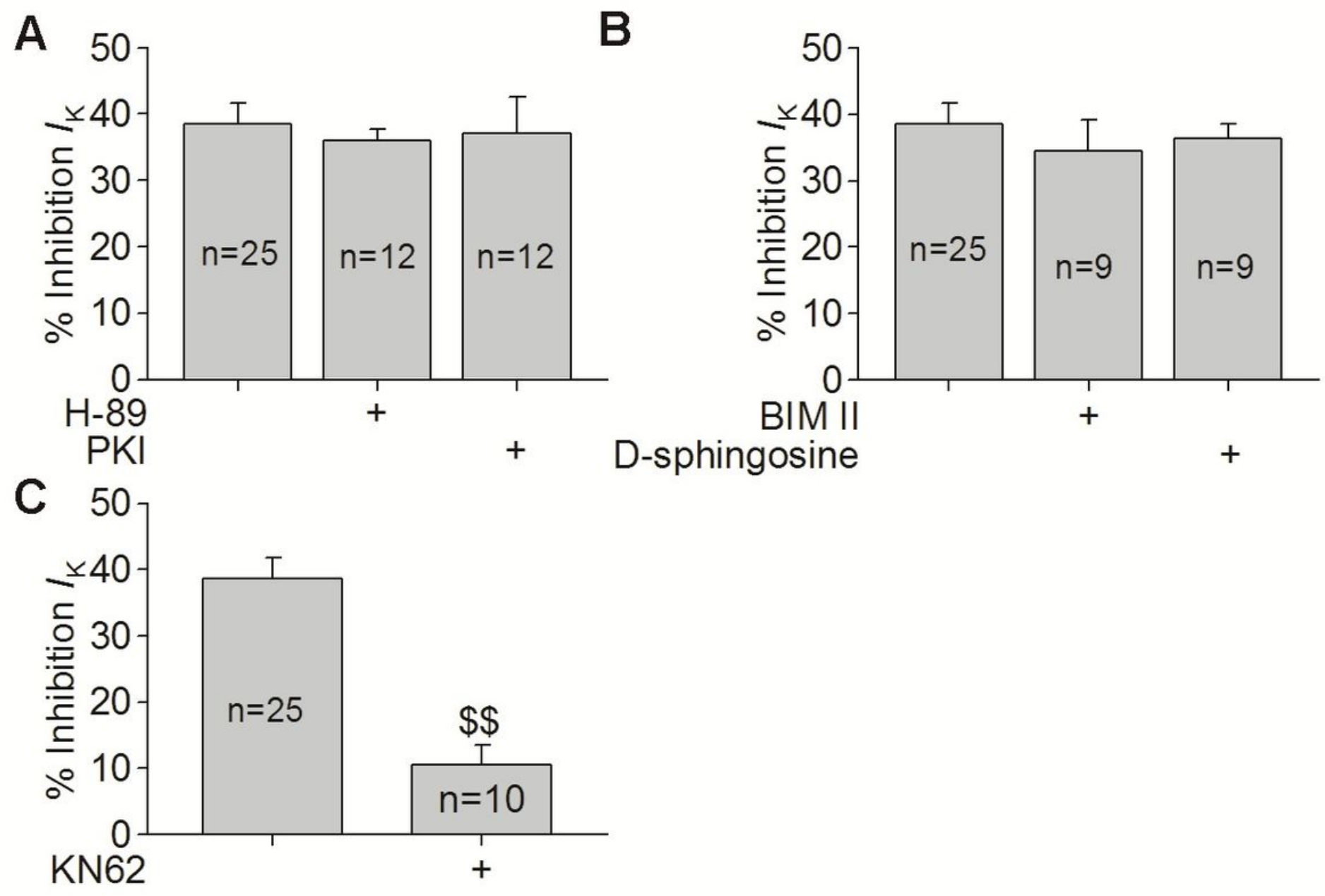

Figure 4

Involvement of CaMKII in GSK1016790A-inhibited IK A. In the presence of PKA antagonist H-89 or PKI, GSK1016790A-induced inhibition of IK was unaffected. Unpaired $t$ test, $P>0.05$ in each case $B$. Preapplication of PKC antagonist BIM II or D-sphingosine, IK was inhibited $34.49 \pm 4.76 \%(n=9)$ and $36.35 \pm 2.19 \%(n=9)$ by GSK1016790A, respectively. Unpaired $t$ test, $P>0.05$ in each case $C$. In the presence of CaMKII antagonist KN-62, GSK1016790A-induced inhibition of IK was markedly blocked. Unpaired t test, \$\$P<0.01 vs. GSK1016790A 

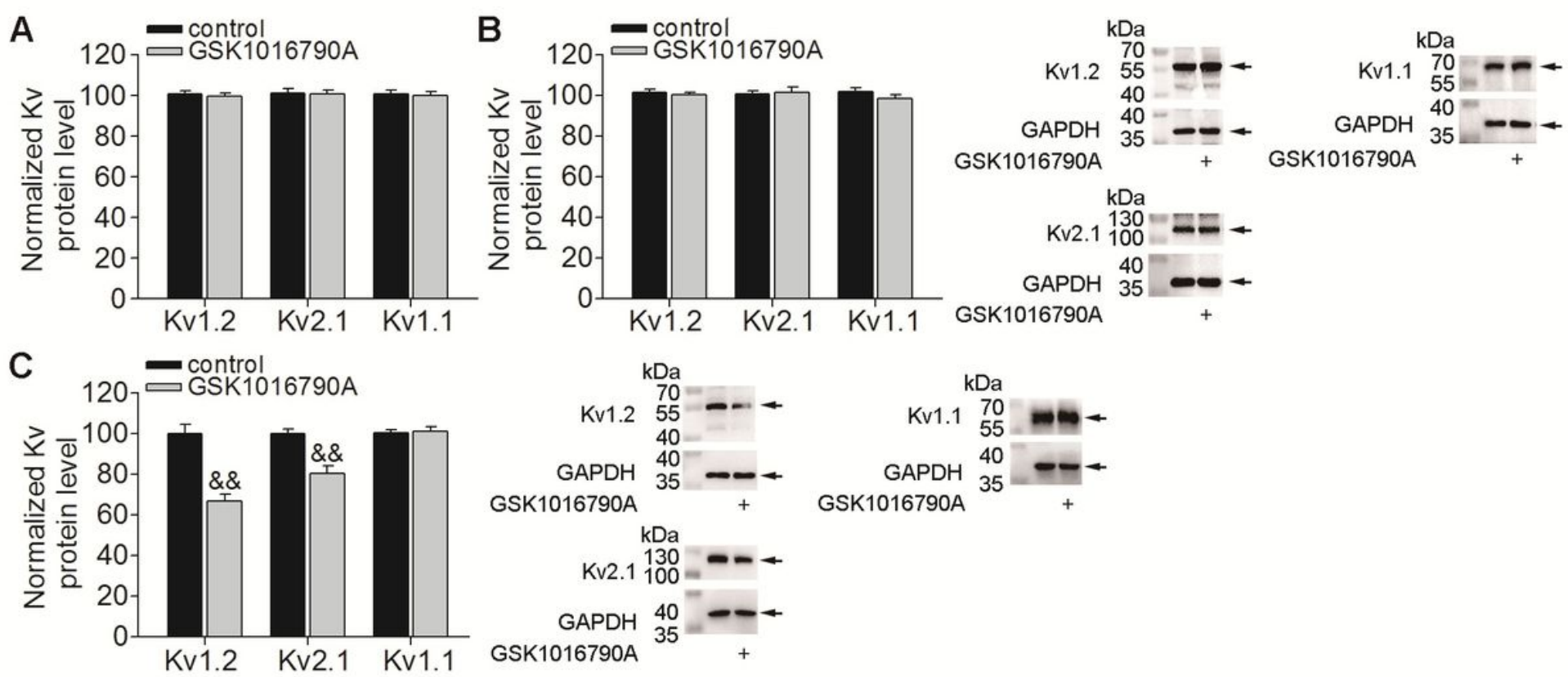

Figure 5

Effect of GSK1016790A on the protein level of Kv subunits in hippocampi A-C. The hippocampal protein levels of Kv1.2, Kv2.1 and Kv1.1 were not affected by application of GSK1016790A for 30 min or $1 \mathrm{~h}$. DF. The hippocampal protein levels of Kv1.2, Kv2.1 reduced in mice injected with GSK1016790A for $3 \mathrm{~d}$, but that of Kv1.1 did not change. Unpaired t test, ${ }^{\wedge \wedge} \mathrm{P}<0.01$ vs. control 
A

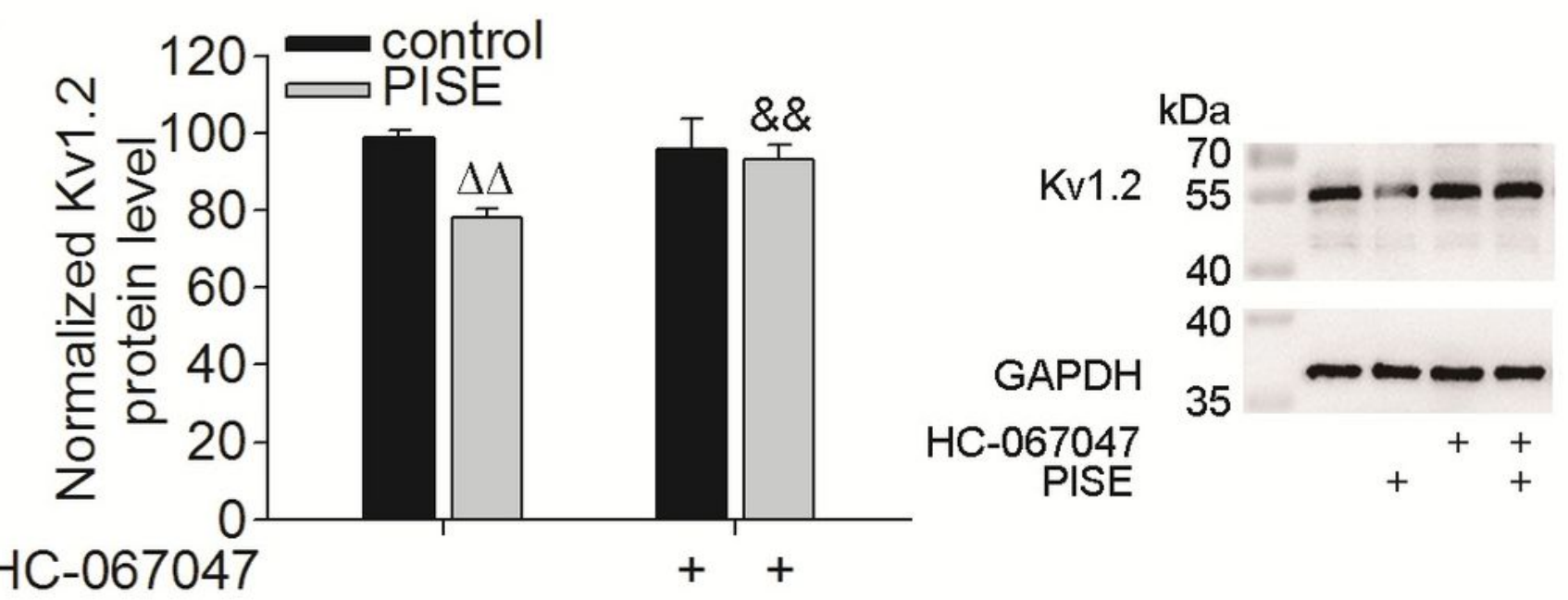

B
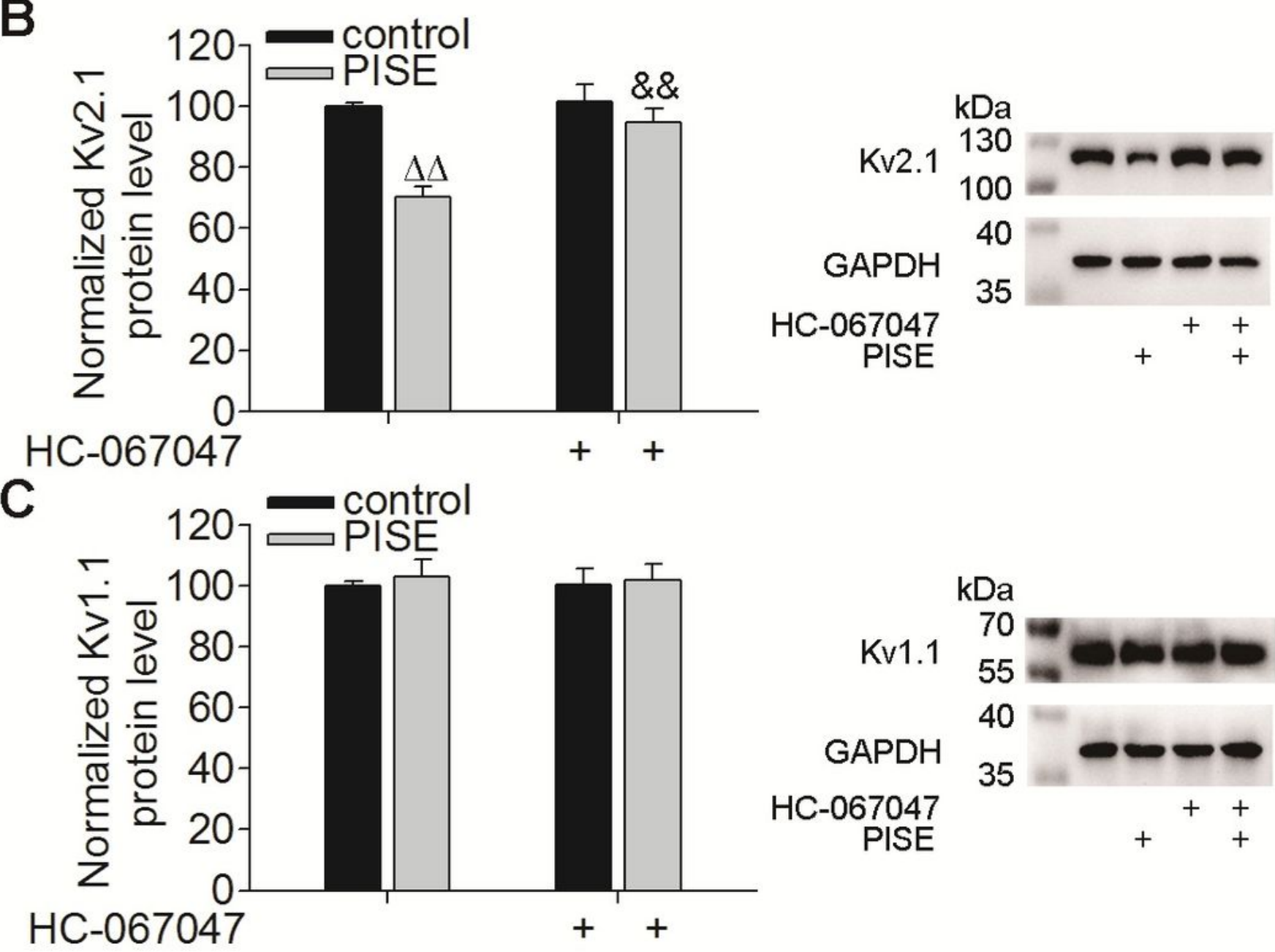

Figure 6

Changes of Kv subunits protein levels in hippocampi post PISE The hippocampal protein levels of Kv1.2 (A) and Kv2.1 (B) reduced markedly post PISE, which was markedly blocked by application of HC-067047. The hippocampal protein level of Kv1.1 (C) did not changed post PISE. ANOVA, $\Delta \Delta \mathrm{P}<0.01$ vs. control, $\& \& P<0.01$ vs. PISE 